\title{
Laser-Assisted Wet Etching of Silicon Back Surfaces Using 1552 nm Femtosecond Laser
}

\author{
Khanh Phu Luong*, Rie Tanabe-Yamagishi**, Noboru Yamada* and Yoshiro Ito*
}

(Received Oct. 14, 2019)

\begin{abstract}
*Department of Mechanical Engineering, Nagaoka University of Technology, 1603-1, Kamitomioka, Nagaoka, Niigata 940-2188, Japan

**Department of Intelligent Mechanical Engineering, Fukuoka Institute of Technology, 3-30-1 Wajiro- higashi, Higashi-ku, Fukuoka 811-0295, Japan
\end{abstract}

\begin{abstract}
Efficient three-dimensional (3D) microfabrication techniques of an $\mathrm{Si}$ are in high demand for producing micrometer-scale 3D structures. Here, we report a new method for processing Si back surfaces using a $1552.5 \mathrm{~nm}$ femtosecond laser. As the Si is optically transparent at this wavelength, we attempted to machine the Si back surfaces via a nonlinear absorption process using the laser. Given that the etch rate of the back surface would be higher, wet etching was performed using an aqueous $\mathrm{KOH}$ solution. The $40 \% \mathrm{KOH}$ solution was maintained in contact with the Si back surface at $25^{\circ} \mathrm{C}$ while the laser was irradiated from the front surface. The laser beam was focused on the back surface and linearly scanned under different conditions. Focusing the laser approximately 15 $\mu \mathrm{m}$ into the liquid yielded deeper grooves as compared to those when it was focused precisely on the Si back surface. Further, the etch rate was significantly higher compared to that during dry etching. We could achieve the maximum etch depth of approximately $6 \mu \mathrm{m}$ during the wet etching process, in contrast to $0.3 \mu \mathrm{m}$ during dry etching. However, the groove depth was not constant along the processing path. The results demonstrate a possibility of a new, efficient, and debris-free microfabrication technique.
\end{abstract}

Key words: Silicon, back surface, femtosecond laser, wet etching, potassium hydroxide solution

\section{INTRODUCTION}

Silicon is a key material in many modern devices such as electronic circuits, solar cells, and microelectromechanical systems, to name a few. Even though several techniques are available for the fabrication of these silicon-based devices, efficient three-dimensional (3D) microfabrication techniques in particular are in high demand, especially for producing micrometer-scale 3D structures ${ }^{1)-3)}$.

Wet etching during laser irradiation is one such technique. The laser irradiation process can modify the rate of etching of Si by an etchant. Thus, by combining laser irradiation and treatment with an etchant, one can produce 3D structures on $\mathrm{Si}$ substrates. However, this process is a multistep one and usually takes a lot of time $^{4)}$. Further, while the etch rate of Si during laserassisted wet etching is higher than that during etching in the absence of a laser, there are a few problems with the practical applicability of this method. For instance, the laser is usually irradiated onto the substrate through a liquid layer. This inevitably results in thermally induced bubbles near the position of irradiation. These phenomena can block or distort the incoming laser beam, resulting in unsteady and uncontrollable processing ${ }^{5)}$. In addition, laser irradiation on a liquid layer perturbs the free liquid surface, resulting in the uncontrollable reflection /refraction of the incoming laser beam ${ }^{6}$. Furthermore, the debris produced tends to get deposited or suspended near the position or within the machined structure.

By performing wet etching on the back surfaces of the $\mathrm{Si}$ substrates, one can avoid these problems. Niino's group proposed laser-induced backside wet etching for the 3D machining of transparent substrates. In this process, a pulsed laser is irradiated onto the substrate and is absorbed by the liquid that is in contact with the back surface of the substrate; this produces a laser-induced plasma, which machines the substrate ${ }^{7)}$, ${ }^{8)}$. In addition, it is a debris-free process.

The 3D laser processing of transparent dielectric materials by short-pulse lasers via nonlinear absorption processes is also an established method for fabricating 3D structures on or within these materials $^{9)-11)}$. We had shown previously that $\mathrm{Si}$ substrates are transparent to laser radiation at 1552.5 $\mathrm{nm}$ and that the laser processing of other materials located behind the $\mathrm{Si}$ substrate is possible using a pulsed laser. When pulses of a femtosecond $1552.5 \mathrm{~nm}$ laser are focused on materials such as $\mathrm{Si}$, quartz crystals, or thin gold films through a single crystal $\mathrm{Si}$ substrate placed in front, the target can be processed through the Si substrate without causing any change in the Si substrate through which the laser is irradiated ${ }^{12)}$ 14). Thus, we can consider the Si substrate as being a "transparent" window at this wavelength. Based on these results, we attempted the 3D laser processing of both the interior and the backside of Si substrates using a femtosecond $1552.5 \mathrm{~nm}$ laser. While the preliminary results have been reported elsewhere ${ }^{14)}$, 15), we encountered difficulties during the experiments, which 
included a low machining rate and unsteady processing.

To achieve higher etch rates, we attempted the wet etching of the backsides of Si substrates by focusing a femtosecond $1552.5 \mathrm{~nm}$ laser onto the back surface of an Si substrate. The back surfaces of the Si substrates were maintained in contact with an etchant liquid. Thus, it was possible to avoid the problems encountered during conventional laser-assisted wet etching ${ }^{15}$. Liu et. al. reported the processing of the back surfaces of $\mathrm{Si}$ wafers with nanosecond $\mathrm{Nd}$ :YAG laser pulses in air ${ }^{16)}$. They reported the melting and transition of crystalline $\mathrm{Si}$ into oxidized and amorphous Si by heating via linear absorption of the laser radiation, because Si weakly absorbed the laser radiation of $1064 \mathrm{~nm}$. Here, we report the results of further attempts at the wet etching of the back surfaces of Si substrates by irradiation with the pulses of a femtosecond $1552.5 \mathrm{~nm}$ laser through the substrates. The absorption of the laser radiation by $\mathrm{Si}$ is considered to be a non-linear process and thus more localized processing would occur.

\section{EXPERIMENTAL}

A schematic diagram of the laser irradiation system used is shown in Fig. 1. We employed an infrared (IR) femtosecond fiber laser (Discovery 1552-5, Raydiance) in this study. The irradiation system was operated at frequencies, $f$, of $1 \mathrm{~Hz}$ to $500 \mathrm{kHz}$ and pulse energies of $1 \mu \mathrm{J}$ to $5 \mu \mathrm{J}$. The pulse width was 900 $\mathrm{fs}$, and the central wavelength was $1552.5 \mathrm{~nm}$. The laser pulses were passed through an IR microscope via the side arm using two mirrors and then focused. A visible-IR camera (ARTCAM-130MI-HDM-NIR, Artray) was installed along the observing optical axis. This setup made it possible to perform laser irradiation while observing the back surface of the test $\mathrm{Si}$ substrate using the IR camera. A dichroic mirror was installed inside the microscopy system such that the wavelength of incident laser radiation, $1552.5 \mathrm{~nm}$, was reflected to an objective lens but that of the observed light, 700-1200 nm, was transmitted to an eyepiece. For the IR observations, we used an IR filter to observe the Si substrate using $1100 \mathrm{~nm}$ light.

An objective lens $(\times 100$, numerical aperture of 0.85 ) equipped with a correction collar was used in order to minimize the aberrations arising from the high refractive index of $\mathrm{Si}(3.47 \text { at } 1552 \mathrm{~nm})^{17}$. When a marking on the back surface of the Si substrate could be observed clearly after adjusting both the lens and the collection collar, it was assumed that the laser beam was focused on the back surface; this position was taken to be $\pm 0 \mu \mathrm{m}$. Focus positions that lay below the back surface, that was in the liquid phase, were denoted using the minus (-) sign (e.g., $-5 \mu \mathrm{m}$ ). Additional adjustments were made to the collection collar, given the slight difference in the refractive indices at the laser and observation wavelengths (3.47 at $1552 \mathrm{~nm}$ and 3.53 at $1100 \mathrm{~nm})^{17), 18)}$.

Owing to the size of the laser beam and the acceptance diameter of the microscope as well as other losses, the measured energy of the laser pulses emitted from the objective lens was approximately one-fifth of that at the exit of the laser. In this study, we maintained the laser pulse energy at $4 \mu \mathrm{J}$, which reduced to approximately $0.8 \mu \mathrm{J}$ after the objective lens.

Double-sided polished P-type Si substrates with a thickness of $320 \mu \mathrm{m}$ and having the (100) crystal orientation were used in this study. The bandgap energy of single-crystal $\mathrm{Si}$ is $1.12 \mathrm{eV}^{19)}$. Further, the extinction coefficient of $\mathrm{Si}$ at the wavelength of 1552 $\mathrm{nm}$ is effectively zero. Hence, the $\mathrm{Si}$ is considered a transparent material in this IR region. Given that the etch rate at the Si back surface would be higher, wet etching using an aqueous $\mathrm{KOH}$ solution was performed. During the wet etching process, a $40 \%$ $\mathrm{KOH}$ solution at $25^{\circ} \mathrm{C}$ was maintained in contact with the $\mathrm{Si}$ back surface, while the laser was irradiated from its front surface.

During trial experiments, we observed that bubbles formed during the irradiation process and that they prevented stable contact between the $\mathrm{Si}$ substrate surface and the $\mathrm{KOH}$ solution, resulting in nonuniform grooves along the processing path ${ }^{15}$. Therefore, we designed an irradiation cell, which is shown in Fig. 2. The Si substrate $(20 \mathrm{~mm} \times 20 \mathrm{~mm})$ was placed on the top of the liquid cell, in which the $40 \% \mathrm{KOH}$ solution was circulated continuously using a pump. The back surface of the substrate was in complete contact with the etchant liquid such that the flowing liquid carried away the bubbles formed at the irradiated position. The sample cell could be moved using a motorized electric stage (ALS-602-H0M, Chuo Precision Industrial Co. Ltd.). During the scanning process, the sample was driven $500 \mu \mathrm{m}$ in the $\mathrm{x}$-direction and then moved $50 \mu \mathrm{m}$ in the y-direction. After the completion of the irradiation process, the front and back surfaces of the sample were observed with an IR microscope, a laser microscope (VK-8710, KEYENCE), and a scanning electron microscopy (SEM) system.

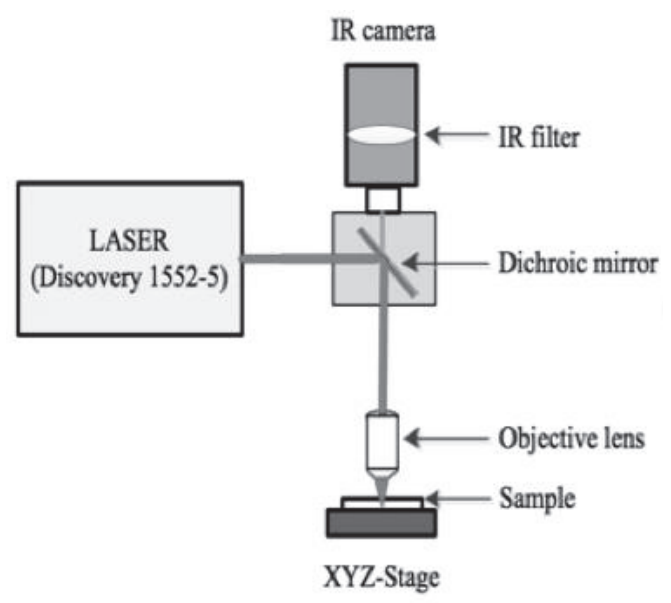

Fig. 1 Schematic of experimental setup used in this study. 


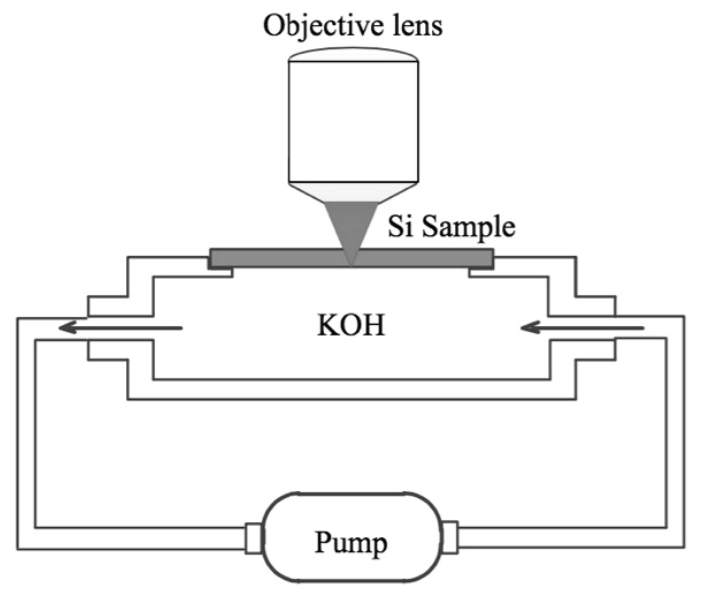

Fig. 2 Schematic of irradiation cell with flow system.

\section{RESULTS AND DISCUSSIONS}

\subsection{Laser-Assisted Wet Etching on Si Back Surface with $\mathrm{KOH}$ Solution}

Figure 3 shows optical micrographs of the Si back surfaces obtained at visible-range and IR wavelengths after wet etching during irradiation at $f=500 \mathrm{kHz}$; the scanning speed $(v)$ was $50 \mu \mathrm{m} / \mathrm{s}$ and the focus position was at $-15 \mu \mathrm{m}$. We would like to emphasize here that there was no observable change on the front surface of the Si substrate, where the irradiated laser was incident. The laser scans appeared as black in the visible-light and IR images were the grooves etched on the back surface. In the visible-light images, only the changes that had occurred on the back surface could be observed. Thick black parts corresponded to deep grooves as shown in Fig. 3 while thinner straight lines were shallow grooves. Also, we did not observe any debris sticking around the processed lines as expected for a backside wet etching. This indicated that this method was a debris-free one. On the other hand, in the IR images, at some parts, slightly thicker gray lines appeared along the scan lines with thinner black parts. As reported in our dry-etching study, the gray parts observed with IR light are the changes occurring only inside Si. The IR images showed the changes that had occurred both on the back surface and within the substrate, in keeping with a previous report ${ }^{20)}$. We quantified the percentage changes that had occurred on the back surface by dividing the total length of the black lines observed in the visible-range images by the total length of the processing path. Even though a flow system had been used to avoid a bubble formation, the groove depth showed variations, ranging from a few hundred nanometers to a few micrometers. The etch rate was significantly higher compared to that during dry etching ${ }^{15), 20)}$. In case of wet etching, at some positions, the maximum etch depth was nearly $8 \mu \mathrm{m}$, compared to the maximum of $150 \mathrm{~nm}$ in case of dry etching. However, as stated above, the etch depth along the processing path showed significant variations.

It was expected that the $\mathrm{KOH}$ solution would have an effect on the Si substrate even in the absence of laser irradiation. In the irradiation system used in this study, the Si back surface was in contact with the solution for some time prior to the laser irradiation process, and this contact period increased from the start position of the laser scan to its end. We defined the pre-etch time as the period for which the Si back surface and the $\mathrm{KOH}$ solution were in contact before the start of the laser irradiation process. In our experiments, the pre-etch time was $60 \mathrm{~s}$, after which the irradiation process was started. Further, the preetch time increased from the top to the bottom for the scans performed in this order.

We measured the etch depth of the black area marked with the circle in Fig. 3 using a laser microscope; the pre-etch time in this case was $450 \mathrm{~s}$. Figure 4 shows the depth profile along a length of 142 $\mu \mathrm{m}$ at the center of the black area. We considered the distance between the lowest part to the surface of the $\mathrm{Si}$ substrate to be the etch depth. The maximum groove depth was approximately $7.76 \mu \mathrm{m}$. The depth varied significantly along the processing path, even though no bubble was observed on the back surface during irradiation either with a naked eye or using an IR camera. Moreover, even when the focus position, $f$, and $v$ were changed, similar variations were observed. The same variations in etch depth were observed for dry etching case but the absolute depth was much shallower than wet etching case ${ }^{20)}$.

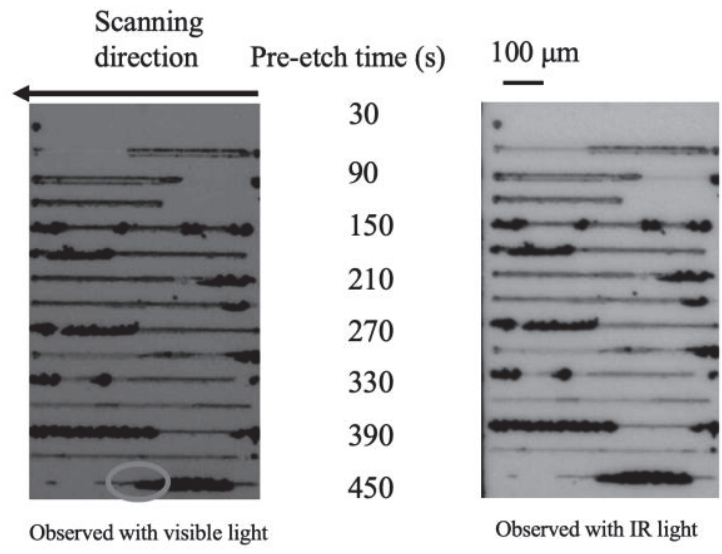

Fig. 3 Visible-light (left) and IR (right) microscopy images of Si back surface after wet etching at $f=500$ $\mathrm{kHz}$ and $\nu=50 \mu \mathrm{m} / \mathrm{s}$ at $-15 \mu \mathrm{m}$ focus position.

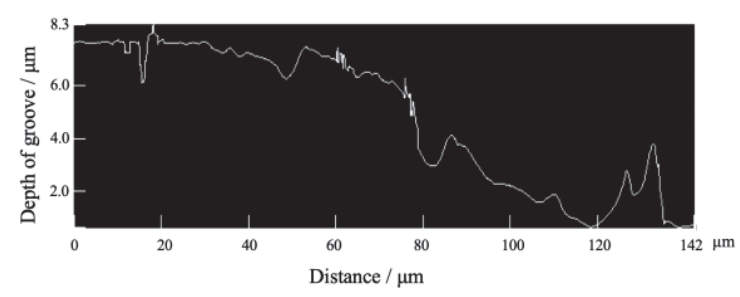

Fig. 4 Depth profile of $142-\mu \mathrm{m}$-long section at center part of processing line for pre-etch time of $450 \mathrm{~s}$. Position corresponds to circle in Fig. 3.

\subsection{Effects of Focus Position}


Figure 5 shows visible-light and IR images of the back surface subjected to wet etching at the same $f$ and $v$; however, in this case, the laser was irradiated at the $0 \mu \mathrm{m}$ focus position. The lines in the visible-light image were narrower and fainter compared to those shown in Fig. 3. In addition, the lines were not continuous but intermittent, and there was no thick part, indicating that the etch depth was less than that in the case for a focus position of $-15 \mu \mathrm{m}$. In the IR image, the black dotted lines, which corresponded to those observed in the visible-light image, overlapped with wider, continuous gray bands. These gray bands represented the changes that occurred within the $\mathrm{Si}$ substrate and were not observed in the images in Fig. 3 , which corresponded to a focus position of $-15 \mu \mathrm{m}$. The depth of the grooves formed at a focus position of $0 \mu \mathrm{m}$ was approximately $300 \mathrm{~nm}$ and shallower than that of the grooves formed at $-15 \mu \mathrm{m}$ but greater than that of grooves formed by the dry etching of the back surface (approximately $150 \mathrm{~nm})^{20)}$. Thus, the focus position of $-15 \mu \mathrm{m}$ resulted in a higher etch rate (deeper grooves) compared to the $0 \mu \mathrm{m}$ position. We tried other focus positions as well, namely, -12, -9, -6, -3 , and $+3 \mu \mathrm{m}$. For long enough pre-etch time (360 s and longer), at the $-12 \mu \mathrm{m}$ focus position, we could achieve an etch depth of $8 \mu \mathrm{m}$ at some points along the processing path. However, when the focus position was moved closer to the Si back surface, the maximum depth decreased. When we set the focus position to be within the $\mathrm{Si}$ substrate $(+3 \mu \mathrm{m})$, the maximum etch depth on the $\mathrm{Si}$ back surface was very small, approximately $300 \mathrm{~nm}$. Thus, it can be concluded that the laser must be focused at a point that lies beneath the etchant surface in order to increase the etch rate.

By performing laser-assisted wet etching on the back surfaces of Si substrates, we could form grooves with greater depths than that formed by dry etching. However, the depth of the grooves was not constant. For the same $v$ and $f$ values and focus position, the depth along the same processing path varied significantly from point to point. Even though the changes induced on the Si back surfaces were more uniform after the wet etching process than dry etching, we could not etch uniform and continuous deep grooves.

The etch rate at the $-15 \mu \mathrm{m}$ focus position was greater than that at the $0 \mu \mathrm{m}$ position, even though the power density at the back surface was much lower in the former case. This contradictory result can be explained as follows. The optical absorption coefficient of water at $1552 \mathrm{~nm}$ is approximately 9.5 $\mathrm{cm}^{-121)}$, and that of $\mathrm{KOH}$ solution is considered to be similar to that of water. Thus, owing to the high absorption coefficient of water, the aqueous $\mathrm{KOH}$ solution absorbes energy from the laser via a linear absorption process. Given the refraction of the laser light at the silicon-liquid interface, the focus position at $-15 \mu \mathrm{m}$ actually corresponded to a position $6.12 \mu \mathrm{m}$ within the solution below the Si back surface under tight focusing. Thus, a small focal volume of the liquid close to the Si back surface absorbed a large amount of the laser energy, resulting in a rapid increase in its temperature. As a result, the etch rate of Si was high. At the $0 \mu \mathrm{m}$ focus position, similar to dry etching, wherein nonlinear absorption occurred within the $\mathrm{Si}$ substrate near the focus. This decreased the amount of laser energy that reached the focus position ${ }^{20}$. Hence, the temperature of the $\mathrm{KOH}$ solution in contact with the surface was lower than that at $-15 \mu \mathrm{m}$, resulting in shallower depth.

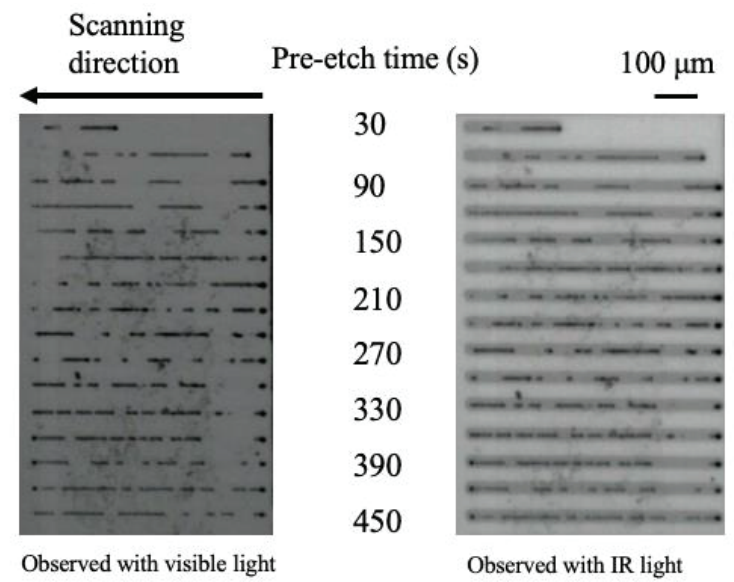

Fig. 5 Optical microscopy images of Si back surface obtained using visible (left) and IR (right) light after wet etching at $f=500 \mathrm{kHz}$ and $v=50 \mu \mathrm{m} / \mathrm{s}$ at $0 \mu \mathrm{m}$ focus position.

\subsection{Effects of Scan Speed $v$ and Laser Repetition Rate $f$}

Figure 6 shows microscopy images of the back surface of the Si substrate after it were subjected to wet etching at the $0 \mu \mathrm{m}$ focus position at $f=500 \mathrm{kHz}$ and different $v$ values: 4 lines at $800 \mu \mathrm{m} / \mathrm{s}, 4$ lines at $400 \mu \mathrm{m} / \mathrm{s}, 4$ lines at $100 \mu \mathrm{m} / \mathrm{s}$, and 2 lines at $20 \mu \mathrm{m} / \mathrm{s}$. Although the pre-etch time inevitably increased from the top lines to the bottom ones, as those shown to Figs. 3 and 5, its effect was not evident in these images. We could form continuous grooves, with the contrast of the lines becoming sharper with a decrease in $v$. At the lowest $v$ value $(20 \mu \mathrm{m} / \mathrm{s})$, dotted lines were observed, suggesting that etching had occurred in a discontinuous manner. The average groove depth was approximately $400 \mathrm{~nm}$ and greater than that for $v=800$

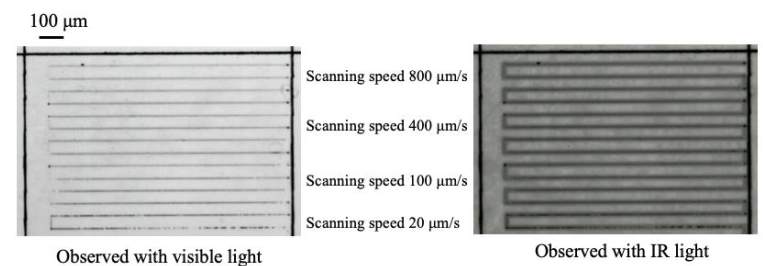

Fig. 6 Visible-light (left) and IR (right) images of Si back surface after wet etching at $f=500 \mathrm{kHz}$ and different $v$ at $0 \mu \mathrm{m}$ focus position. From top to bottom: 4 lines at $800 \mu \mathrm{m} / \mathrm{s}, 4$ lines at $400 \mu \mathrm{m} / \mathrm{s}, 4$ lines at 100 $\mu \mathrm{m} / \mathrm{s}$, and 2 lines at $20 \mu \mathrm{m} / \mathrm{s}$. Black rectangular lines are marking made by direct laser irradiation for adjusting focus. 
$\mu \mathrm{m} / \mathrm{s}$, which was approximately $200 \mathrm{~nm}$. Continuous gray lines were seen in the IR images in addition to the black lines at the center, which corresponded to those observed in the visible-light images. The widths of the gray lines were greater than those of the lines observed in the visible-light images, indicating that the internal changes induced within the substrate had occurred over a wider area than those on the back surface ${ }^{20}$.

We performed laser scans at $v=50 \mu \mathrm{m} / \mathrm{s}$ at the $0 \mu \mathrm{m}$ focus position with different $f: 250 \mathrm{kHz}, 125 \mathrm{kHz}$ and $50 \mathrm{kHz}$. Even at the lowest $f$ value of $50 \mathrm{kHz}$, continuous etch lines were formed. Moreover, the average depth did not change significantly with different $f$ and remained at approximately $250-300 \mathrm{~nm}$ along each processed line. The internal changes observed in the IR images were continuous; however, in this case, the width decreased slightly with the decrease in $f$. Since the number of pulses irradiated at the same spot decreased with the decrease in $f$, the total amount of energy transmitted also decreased, resulting in a smaller internal modified area.

\subsection{Morphology on Back Surface after Wet Etching}

During SEM observations, two types of morphologies were observed after the laser-assisted wet etching at $v=400 \mu \mathrm{m} / \mathrm{s}$ at the $0 \mu \mathrm{m}$ focus position, namely, grooves and periodic structures oriented perpendicular to the laser polarization direction. At the $0 \mu \mathrm{m}$ focus position, for $f=250 \mathrm{kHz}$ and lower, periodic structures were formed, while at $f=500 \mathrm{kHz}$, both grooves and periodic structures were formed. We estimated the periodicity of these structures by measuring the distance between six consecutive parallel lines and dividing it by 5 . The interval was found to be approximately $200 \mathrm{~nm}$, and the depth was approximately $170-300 \mathrm{~nm}$. These values were different from those of the periodic structures formed during dry etching; in this case, the interval was approximately $330 \mathrm{~nm}$, and the structures were oriented parallel to the laser polarization direction ${ }^{20,22)}$ However, when the laser was focused at a position deeper within the $\mathrm{KOH}$ solution, other types of structures were formed. Figure 7 shows SEM images of a processing line after wet etching at $f=500 \mathrm{kHz}$ and $v=50 \mu \mathrm{m} / \mathrm{s}$ at the focus positions of (a) $0 \mu \mathrm{m}$ and (b) $-15 \mu \mathrm{m}$. At the $0 \mu \mathrm{m}$ focus position, the back surface was dominated by periodic structures oriented perpendicular to the laser polarization direction. Meanwhile, at the $-15 \mu \mathrm{m}$ focus position, in some parts of the processing line, we observed periodic structures oriented parallel to the laser polarization direction and having an interval of approximately $1.2 \mu \mathrm{m}$ and depth of $1.3 \mu \mathrm{m}$. Note that magnifications in (a) and (b) are different. Some parts of the line were deep grooves with a depth of up to $5 \mu \mathrm{m}$, with no periodic structures being present. Figure 7 (c) shows an SEM image of a processing line after wet etching at $f=500 \mathrm{kHz}$ and $v$ $=100 \mu \mathrm{m} / \mathrm{s}$ at the $-15 \mu \mathrm{m}$ focus position. Figure 7 (d) showed the center of Fig. 7 (c), at which periodic structures oriented perpendicular to the laser polarization direction and having an interval of
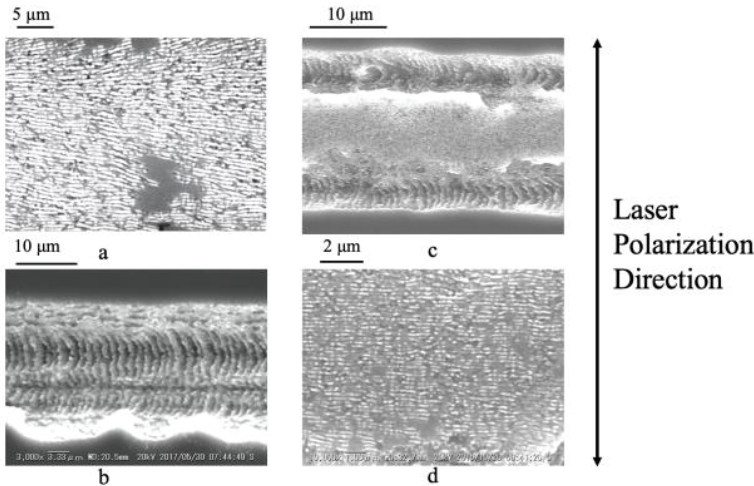

Fig. 7 SEM images of LIPSS formed on Si back surface after wet etching at $f=500 \mathrm{kHz}$ and $v=50$ $\mu \mathrm{m} / \mathrm{s}$ at (a) $0 \mu \mathrm{m}$ and (b) $-15 \mu \mathrm{m}$ focus positions and (c) at $v=100 \mu \mathrm{m} / \mathrm{s}$ at $-15 \mu \mathrm{m}$ focus position. (d) shows the center region of figure (c).

approximately $200 \mathrm{~nm}$ were observed; these were similar to the structures observed at the $0 \mu \mathrm{m}$ focus position shown in (a). The depth of these periodic structures was low at approximately 200-300 nm. However, at the edge of the processing line, periodic structures parallel to the laser polarization direction were observed. Their interval was approximately $1.2-1.3 \mu \mathrm{m}$, and the depth was $0.8-1.5 \mu \mathrm{m}$.

After the wet etching process, we found so-called laser-induced periodic surface structures (LIPSS) or ripples at the bottom of the etched grooves. We believe this is the first instance where LIPSS were formed on the back surface of an $\mathrm{Si}$ substrate in an aqueous solution. There have only been a few studies on the formation of LIPSS at under water conditions 23), 24), and in these previous studies, the LIPSS were formed on the front surface of the Si substrate under direct irradiation. Hence, the formation of LIPSS on the back surfaces of $\mathrm{Si}$ substrates in water is a unique achievement. The formation of LIPSS on materials surfaces is a subject of significant research interest, and a more detailed description of the LIPSS formation on the Si back surfaces can be found elsewhere ${ }^{22)}$.

\section{CONCLUSIONS}

In this study, we performed the laser-assisted wet etching of Si back surfaces using a femtosecond laser at $1552.5 \mathrm{~nm}$. The etch rate on the back surface during the wet etching process was higher than dry etching, resulting in an increase in the groove depth from 300 $\mathrm{nm}$ to approximately $6 \mu \mathrm{m}$. We also examined the effects of laser repetition rate, the scanning speed and focus position on the wet etching process. A focus position approximately $12-15 \mu \mathrm{m}$ below the Si back surface and within the $\mathrm{KOH}$ solution was found to be the most appropriate one for ensuring that the depth of the etched lines was the maximum. However, at the $15 \mu \mathrm{m}$ focus position, which resulted in deeper grooves, the groove depth showed significant variations. At the $0 \mu \mathrm{m}$ focus position, the depth was 
shallower than $-15 \mu \mathrm{m}$ focus position but was deeper with better uniformity than that during dry etching. The morphology of the structural changes induced on the Si back surface by the laser-assisted wet etching method was different from that of the structures machined by the dry etching method ${ }^{20)}$. In the former case, grooves and periodic structures either parallel or perpendicular to the laser polarization direction and having different depths were observed. The underlying formation mechanism of these structures will be

\section{REFERENCES}

[1] X. Q. Liu, L. Yu, Z. C. Ma and Q. D. Chen: Silicon Three-Dimensional Structures Fabricated by Femtosecond Laser Modification with Dry Etching, Applied Optics, Vol.56, No.8, (2017) pp.2157-2161.

[2] S. Yadavali, D. Lee and D. Issadore: Robust Microfabrication of Highly Parallelized ThreeDimensional Microfluidics on Silicon, Scientific Reports 9, 12213 (2019) pp.1-10.

[3] C. M. Waits, B. Morgan, M. Kastantin, and R. Ghodssi: Microfabrication of 3D Silicon MEMS Structures Using Gray-Scale Lithography and Deep Reactive Ion Etching, Sensors and Actuators A: Physical, Vol.119, Issue 1, (2005) pp.245-253.

[4] S. Lee, K. Jo, H. Keum, Sangmin Chae, Y. Kim, J. Choi, H. H. Lee, and H. J. Kim: Nanowall Formation by Maskless Wet-Etching on a Femtosecond Laser Irradiated Silicon Surface, Applied Surface Science, Vol.437, (2018) pp.190194.

[5] S. Kiyama, S. Matsuo, S. Hashimoto, and Y. Morihira: Examination of Etching Agent and Etching Mechanism on Femtosecond Laser Microfabrication of Channels Inside Vitreous Silica Substrates, Journal of Physical Chemistry C, Vol.113, (2009) pp.11560-11566.

[6] M. Pfiffer, P. Cormont, E. Fargin, B. Bousquet, M. Dussauze, S. Lambert and J. Neauport: Effects of Deep Wet Etching in $\mathrm{HF} / \mathrm{HNO}_{3}$ and $\mathrm{KOH}$ Solutions on The Laser Damage Resistance and Surface Quality of Fused Silica Optics at $351 \mathrm{~nm}$, Optics Express, Vol.25, Issue 5, (2017) pp.46074619.

[7] J. Wang, H. Niino, and A. Yabe: Micromachining of Quartz Crystal with Excimer Lasers by LaserInduced Backside Wet Etching, Applied Physics A, Vol.69, No.7, (1999) pp. S271-S273.

[8] J. Wang, H. Niino, and A. Yabe: One-step Microfabrication of Fused Silica by Laser Ablation of An Organic Solution, Applied Physics A, Vol.68, No.1, (1999) pp.111-113.

[9] X. Jia and X. Zhao: Numerical Study of Material Decomposition in Ultrafast Laser Interaction with Metals, Applied Surface Science, Vol.463, (2019) pp.781-790.

[10] Y. Shimotsuma, K. Hirao, P. G. Kazansky and J. Qiu: Three-Dimensional Micro- and Nano- elucidated in a future study. The results demonstrate a possibility of a new, efficient, and debris-free microfabrication technique.

\section{ACKNOWLEDGEMENT}

This work was supported, in part, by the JSPE KAKENHI Grant Nos. 22360060, 26630023 and by the Amada Foundation Grant No. AF-2012214.

Fabrication in Transparent Materials by Femtosecond Laser, Japanese Journal of Applied Physics, Vol.44, No.7a, (2005) pp.4735-4748.

[11]K. Sugioka, Y. Hanada, and K. Midorikawa: 3D Integration of Microcomponents in A Single Glass Chip by Femtosecond Laser Direct Writing for Biochemical Analysis, Applied Surface Science, Vol.253, (2007) pp.6595-6598.

[12] Y. Ito, R. Tanabe, K. Tada: Nonlinear MicroProcessing of Silicon by Ultrafast Fiber Laser at 1552 nm, Materials Research Society Symposia Proceedings, Vol.1365, (2012) pp.31-42.

[13] Y. Ito, Y. Morita, H. Sakashita, R. Suzuki, R. Tanabe, H. Sakurai, K. Tada: Micromachining through Silicon Substrates by Ultrafast Laser at $1552 \mathrm{~nm}$, Proceedings of $31^{\text {st }}$ International Congress on Applications of Lasers and ElectroOptics, Vol.105, (2012) pp.1102-1107.

[14] Y. Ito, H. Sakashita, R. Suzuki, M. Uewada, K. P. Luong and R. Tanabe: Modification and Machining on Back Surface of a Silicon Substrate by Femtosecond Laser Pulses at 1552 nm, Journal of Laser Micro/Nanoengineering, Vol.9, No.2, (2014) pp.98-102.

[15] K. P. Luong, R. Tanabe, and Y. Ito: Machining on Rear Surface of a Silicon Substrate by An Infrared Femtosecond Laser via Non-Linear Absorption Processes, Procedia CIRP, Vol.42, (2016) pp.7376.

[16]N. Liu, J Vincent, K. Moumanis, and J. J. Dubowski: Processing of Back Surface of $\mathrm{Si}$ Wafers with a Pulsed Nd:YAG Laser, Journal of Laser Micro/Nanoengineering, Vol.11, No.2, (2016) pp.232-238.

[17]H. H. Li: Refractive Index of Silicon and Germanium and Its Wavelength and Temperature Derivatives, Journal of Physical and Chemical Reference, Data 9, 561, (1980).

[18] M. A. Green and M. J. Keevers: Optical Properties of Intrinsic Silicon at $300 \mathrm{~K}$, Progress in Photovoltaics: Research and Applications, Vol.3, (1995) pp.189-192.

[19] Y. C. Lam, D. V. Tran, H. Y. Zheng, V. M. Murukeshan, J. C. Chai, and D. E. Hardt: Surface Damage of Crystalline Silicon by Low Fluence Femtosecond Laser Pulses, Surface Review and Letters, Vol.11, (2004) pp.217-221.

[20] K. P. Luong, R. Tanabe-Yamagishi, N. Yamada and Y. Ito: Micromachining of the Back Surface and Interior of Si Using Infrared Femtosecond 
Laser Pulses, Journal of Laser Applications, 32, 012017 (2020); doi: 10.2351/1.5123309

[21] J. A. Curcio and C. C. Petty: The Near Infrared Absorption Spectrum of Liquid Water, Journal of The Optical Society of America, Vol.41, No.5, (1951) pp.302-304.

[22] Y. Ito, S. Y. Chiah, K. P. Luong, D. Kataoka and Rie Tanabe-Yamagishi: Formation of Fine Periodic Structures on Back-Surface of Silicon Substrate by a Femtosecond laser at $1552 \mathrm{~nm}$, Journal of Laser Micro/ Nanoengineering (under review), (2020).

[23] T. Kobayashi, T. Wakabayashi, Y. Takushima and J. Yan: Formation Behavior of Laser-Induced Periodic Surface Structures on Stainless Tool Steel in Various Media, Precision Engineering, Vol.57, (2019) pp.244-252.

[24] G. Miyagi, K. Miyazaki, K. Zhang, T. Yoshifuji and J. Fujita: Mechanism of Femtosecond Laser Induced Periodic Nanostructure Formation on Crystalline Silicon Surface Immersed in Water, Optics Express, Vol.20, No.14, (2012) pp.1484814856. 